\title{
Fenilcetonúria associada à alergia à proteína do leite de vaca
}

\section{Phenylketonuria Associated with Cow Milk Protein Allergy}

\author{
Rafaela Soares Barros de Menezes ${ }^{1} \mathbb{D}$, Erlane Marques Ribeiro ${ }^{2,3}$ (D), Fabiana Maria Silva Coelho ${ }^{3}$ [D, Hildenia Baltasar Ribeiro \\ Nogueira $^{3,4,5}$ (D) \\ 1. Discente do Curso de Medicina do Centro Universitário Christus (UNICHRISTUS), Fortaleza, CE, Brasil. 2. Docente do Curso de Medicina do Centro \\ Universitário Christus (UNICHRISTUS), Fortaleza, CE, Brasil. 3. Hospital Infantil Albert Sabin (HIAS), Fortaleza, CE, Brasil. 4. Docente do curso de Medicina \\ da Universidade de Fortaleza (UNIFOR), Fortaleza, CE, Brasil. 5. Doutoranda pelo Programa de Ciências Morfofuncionais da Universidade Federal do Ceará, \\ Fortaleza, CE, Brasil.
}

\section{Resumo}

Introdução: a fenilcetonúria (PKU) é uma doença do metabolismo da fenilalanina cujo tratamento se baseia na introdução precoce de uma fórmula com restrição de fenilalanina. Relato do caso: uma menina, com diagnóstico de PKU a partir da triagem neonatal, com 82 dias de vida, recebeu tratamento dietético com fórmula com restrição de fenilalanina associada à fórmula láctea e desenvolveu alergia à proteína do leite de vaca (APLV) com sintomas cutâneos e gastrointestinais. Conclusão: o manejo dietético da PKU pode precipitar a ocorrência da APLV.

Palavras-chave: Fenilcetonúrias. Dietoterapia. Fórmulas infantis. Hipersensibilidade a leite.

\begin{abstract}
Introduction: Phenylketonuria (PKU) is a disease of the metabolism of phanylalanine whose treatment is based on the early introduction of a phenylalaninerestricted formula. Case report: A girl with 82 days of life with PKU diagnosis from neonatal screening received dietary treatment with a phenylalaninerestricted formula associated with the milk formula. She developed allergy to cow's milk protein (APLV) with cutaneous symptoms and gastrointestinal disorders. Conclusion: Dietary management of PKU may precipitate the occurrence of APLV.
\end{abstract}

Key words: Phenylketonurias. Diet therapy. Infant formulas. Milk hypersensivity.

\section{INTRODUÇÃO}

A fenilcetonúria (PKU) é uma doença metabólica rara que ocorre quando há deficiência da enzima fenilalanina-hidroxilase, responsável pela transformação da fenilalanina em tirosina ${ }^{1}$. Nesses casos, há hiperfenilalaninemia (HPE) acima de $10 \mathrm{mg} /$ $\mathrm{dl}$, que pode ser detectada por meio da triagem neonatal, permitindo o diagnóstico e o tratamento precoce, mudando a história natural da doença ${ }^{1,2}$.

Apesar de não ser indicada a suspensão do leite materno para o tratamento da PKU, é comum o desmame precoce e o início da fórmula láctea comercial e a fórmula com restrição de fenilalanina como terapia para os pacientes com diagnóstico precoce $^{1}$.

No presente relato, descreveu-se o caso de uma criança com PKU associada à alergia à proteína do leite de vaca (APLV).

\section{RELATO DO CASO}

A menina, procedente da microrregião do Cariri, Ceará, filha de pais não consanguíneos, nascida de parto cesariano sem intercorrências perinatais, recebeu alta da maternidade com prescrição de aleitamento materno exclusivo e orientação para a realização do teste de triagem neonatal, cuja primeira coleta aconteceu com 4 dias de vida. Com 32 dias de vida, houve a liberação do resultado do exame e a confirmação da doença a partir do nível sérico de fenilalanina aumentado, cujo nível sérico de fenilalanina foi $38 \mathrm{mg} / \mathrm{dl}$. A criança teve diagnóstico de fenilcetonúria clássica ${ }^{1,2}$. A família foi contatada pelo serviço que realizou a coleta da triagem neonatal e encaminhou a criança ao serviço de referência estadual de triagem neonatal para início do tratamento.

A primeira consulta ocorreu após $48 \mathrm{~h}$ da solicitação do agendamento pela Secretaria de Saúde do Estado, porém a criança estava com 40 dias de vida. A mãe recebeu aconselhamento genético e orientação dietética para continuar com aleitamento materno e iniciar a dieta com fórmula específica para tratamento de HPE na primeira infância. Com 82 dias de vida, o aleitamento materno foi insuficiente, sendo necessário adicionar a fórmula láctea à dieta. Aos 90 dias de vida, a criança teve febre e diarreia, sendo orientada por outro 
serviço a suspender a fórmula para tratamento de HPE.

A mãe compareceu ao centro de referência estadual de triagem neonatal com a paciente aos 180 dias de vida a fim de retomar a terapia, pois a criança "não estava bem". Foi evidenciado ganho de peso insuficiente, HPE e anemia ferropriva. Foi indicado sulfato ferroso, a dieta específica para HPE foi reintroduzida, e as orientações quanto à importância de cumprir a dieta para PKU foram repassadas à mãe.

Com 5 meses, a criança mantinha palidez cutânea, déficit ponderoestatural, episódios de vômitos, irritabilidade e má aceitação da dieta. A esse quadro se associou perda de cabelo, adinamia e atraso do desenvolvimento neurológico.

Os profissionais de saúde suspeitaram de alergia à proteína do leite de vaca (APLV), substituíram a fórmula láctea por fórmula de soja e encaminharam a criança ao serviço de gastroenterologia. O quadro clínico persistiu, porém com menor gravidade e, na consulta com o especialista, a mãe recebeu a orientação para substituir a fórmula de soja por fórmula extensamente hidrolisada.

Após a mudança de conduta, a paciente evoluiu com melhora do quadro clínico e neurológico. No entanto, o desenvolvimento neuropsicomotor já estava comprometido, principalmente com o comprometimento da linguagem, apesar da terapia de reabilitação implementada. A criança foi alfabetizada, mas houve dificuldade com a leitura/escrita e matemática, evoluindo com atraso no desempenho escolar.

A paciente continua em acompanhamento por uma equipe multidisciplinar. A família seguiu as orientações médicas de forma correta, o que fez que os níveis séricos de fenilalanina reduzissem. A reintrodução do leite de vaca pode ser realizada posteriormente, sem desencadear o quadro clínico inicial.

\section{DISCUSSÃO}

PKU é um erro inato do metabolismo de herança autossômica recessiva, para o qual foi estabelecida uma estratégia de rastreio no período neonatal, a qual permite o diagnóstico e o tratamento precoce, evitando, principalmente, o dano neurológico ${ }^{1-3}$. A incidência de PKU é 1:25.000 no Brasil, sendo a doença metabólica mais comum entre as aminoacidopatias ${ }^{3}$.

Por ser uma doença hereditária, faz parte das boas práticas de atendimento clínico encaminhar os pacientes e suas respectivas famílias para aconselhamento genético, o que foi feito no caso apresentado. Por ser uma doença autossômica recessiva, foi dado o risco de recorrência de $25 \%$ para os pais ${ }^{1}$. No entanto, como o aconselhamento genético é não diretivo, a família tem autonomia para decidir se deseja ter outros filhos, mesmo orientada sobre o risco alto de recorrência, de acordo como princípio da autonomia.

No caso que apresentamos, houve a demora para o diagnóstico e o início do tratamento, o que deve ser interpretado como um problema de saúde pública.

Entre os desafios para o tratamento da HPE está a falta de adesão da família ao tratamento ${ }^{3}$, como aconteceu no caso relatado cuja adesão ficou prejudicada devido às falhas no sistema de saúde pública. Alguns fatores predispõem a isso, como: (1) falta do conhecimento da sociedade e dos médicos quanto às graves consequências da doença, (2) negação da família quanto à existência de uma doença genética que não apresenta manifestações clínicas, (3) dificuldades socioeconômicas para comparecer às consultas agendadas e (4) falhas no sistema de saúde pública, como o atraso do diagnóstico e do início do tratamento.

Com uma taxa de cobertura da triagem neonatal de $82,05 \%$ para o Estado do Ceará em $2011^{4}$ acima da nacional para o mesmo ano $(81,43 \%)^{5}$, o programa estadual ainda tem algumas deficiências, como a demora entre a realização da coleta do material biológico para os testes da triagem neonatal e o recebimento do resultado, que, no caso apresentado, foi maior do que 30 dias, sendo considerado inadequado.

Outra falha do programa estadual é a falta de treinamento dos profissionais envolvidos na triagem neonatal, desde o conhecimento da importância do exame até a falta de empatia ao dar a notícia, que pode ser impactante para a família.

O fato de a criança ser procedente de uma área distante do centro de referência tem um impacto negativo na terapia, tornando-se mais um desafio, pois, apesar de as famílias terem o direito garantido em lei para auxílio fora domicílio, a maioria dos pacientes tem dificuldade para conseguir transporte do município onde mora ao centro de referência para tratamento.

No caso relatado, a criança poderia ter-se beneficiado caso os profissionais responsáveis pela saúde primária e os especialistas tivessem um relacionamento maior com troca de informações sobre a paciente, o que pode ser idealizado com as vantagens que a tecnologia pode oferecer, como um sistema integrado de dados que, além de facilitar a aquisição de informações sobre o paciente em qualquer unidade de saúde, possibilitaria a informação entre os profissionais, tornando-os uma verdadeira equipe, mesmo os profissionais que moram distantes.

É importante salientar que a interferência no tratamento orientado por um especialista, mesmo por desconhecimento da patologia, engloba uma discussão em torno de ética profissional, principalmente se o médico não tem a experiência para manejar a doença de base, podendo resultar em imperícia, negligência e/ou imprudência ${ }^{6}$, pois o tratamento da HPE é para toda a vida $^{1,2}$, e a ausência do tratamento leva à lesão neurológica ${ }^{2,3}$. No caso, a paciente teve atraso de desenvolvimento neurológico, recuperado com a terapia, porém de forma parcial, sendo prejudicada no desempenho escolar.

Quanto à dieta, na tentativa de reduzir os custos com o 
tratamento e utilizar as vantagens do aleitamento materno, os profissionais do Brasil mantêm o aleitamento materno parcialmente nos casos de HPE ${ }^{1}$. Porém, é inevitável o desmame precoce quando o aleitamento materno não é exclusivo. Devido à PKU, foi necessário introduzir a fórmula com restrição de fenilalanina e o leite artificial, que tem a proteína do leite de vaca. Nesse momento, expõe-se a criança ao desenvolvimento da alergia à proteína do leite de vaca.

A alergia alimentar é definida como uma doença consequente de uma resposta imunológica anômala que ocorre após o contato com determinado alimento, seja este ingerido ou não. Conforme a Associação Brasileira de Alergia e Imunologia (ASBAI) e a Sociedade Brasileira de Pediatria (SBP), no Consenso Brasileiro sobre Alergia Alimentar de 20187, atualmente, a alergia alimentar é considerada um problema de saúde pública, pois a sua prevalência tem aumentado no mundo todo.

Quando há uma intercorrência durante uma terapia, é comum tentar o raciocínio de que todas as alterações fazem parte de uma mesma doença. Isso pode atrasar a suspeita diagnóstica de uma condição coexistente, como aconteceu no caso relatado.

A APLV é comum em pediatria e vem aumentando em frequência, por mudança de comportamento da sociedade, predispondo a um desmame precoce ${ }^{8}$. No entanto, a ocorrência da APLV em pacientes com PKU não é relatada na literatura.

No Brasil, a incidência de alergia às proteínas do leite de vaca é de $2.2 \%$ e a prevalência de $5,4 \%$; ; a maioria apresenta sintomas gastrointestinais ${ }^{7-9}$, como no caso que foi relatado, porém pode haver manifestações de outros sistemas em associação. Esses sintomas podem ser cutâneos, respiratórios e sistêmicos ${ }^{8}$.

As alterações gastrointestinais ocorrem em 32-60\% dos casos na APLV, e as mais comuns são vômitos, diarreia ou constipação, irritabilidade, recusa alimentar, dor abdominal ${ }^{9}$, como apresentou a paciente cujo caso foi apresentado. Essas alterações, de forma crônica, podem determinar anemia e desnutrição ${ }^{9,10}$, justificando o quadro clínico da paciente do relato.

O tratamento da APLV é baseado na melhora dos sintomas após a retirada do fator alergênico ${ }^{10}$, como foi feito nesse caso, com a substituição da fórmula láctea pelo hidrolisado proteico. Atualmente, a introdução da fórmula de soja para tratamento da APLV não é recomendada no Brasil para crianças abaixo de 6 meses, segundo as orientações do Protocolo Clínico e das Diretrizes Terapêuticas Alergia à Proteína do Leite de Vaca (APLV) do Ministério da Saúde de $2017^{11}$ e o Consenso Brasileiro sobre Alergia Alimentar de 20187, elaborado pela Sociedade Brasileira de Pediatria e Associação Brasileira de Alergia e Imunologia. No caso que se relatou, a paciente teve sucesso na terapia, tanto da PKU como da APLV, em que a reintrodução do leite de vaca pode ser realizada sem as complicações ocorridas anteriormente, como acontece na maioria dos casos de APLV.

Em resumo, a partir da descrição desse caso, chamou-se a atenção dos profissionais de saúde para a possibilidade do desenvolvimento de sinais clínicos sugestivos de APLV precipitados pelo manejo dietético da fenilcetonúria.

\section{REFERÊNCIAS}

1. Ministério da Saúde [BR]. Protocolos clínicos e diretrizes terapêuticas para fenilcetonúria. Portaria SAS/MS no 1307 de 22 de novembro de 2013. Brasília: Ministério da Saúde; 2014 [acesso 2018 Maio 24]. Disponível em: http:// portalarquivos.saude.gov.br/images/pdf/2014/abril/02/pcdt-fenilcetonurialivro-2013.pdf.

2. Van Wegberg AMJ, MacDonald A, Ahring K, Bélanger-Quitana A, Blau N, Bosch $\mathrm{AM}$ et al. The complete European Guidelines on phenylketonuria: diagnosis and treatment. Orp J Rare Dis [internet] 2017 [cited 2018 May 24]; 12: 162. Avaliable from: https://www.ncbi.nlm.nih.gov/pmc/articles/PMC5639803/ pdf/13023_2017_Article_685.pdf.

3. Vieira E Neto, Maia HS Filho, Monteiro CB, Carvalho LM, Tonon T, Vanz AP et al. Quality of life and adherence to treatment in early-treated Brazilian phenilketonuria pediatric patients. Braz J Med Biol Res [internet]. 2018 Dec [cited 2018 May 24]; 51(2): e6709. Avaliable from: https://www.ncbi.nlm.nih. gov/pmc/articles/PMC5731329/pdf/1414-431X-bjmbr-1414-431X20176709. pdf.

4. Ministério da Saúde [BR]. Indicadores Consolidados para o Estado do Ceará. Brasília: Ministério da Saúde; 2016 [acesso 2018 outubro 10]. Disponível em: http://portalarquivos.saude.gov.br/images/pdf/2016/outubro/programanacional-triagem-neonatal/ceara.pdf.

5. Ministério da Saúde [BR]. Indicadores da Triagem Neonatal no Brasil. Brasília: Ministério da Saúde; 2018 [acesso 2018 outubro 10]. Disponível em: http:// portalms.saude.gov.br/acoes-e-programas/programa-nacional-da-triagemneonatal/indicadores-da-triagem-neonatal-no-brasil.
6. Conselho Federal de Medicina.Código de ética médica. Brasília: CFM; [acesso 2018 Maio 24]. Disponível em: http://www.rcem.cfm.org.br/index.php/cematual\#cap7.

7. Solé D, Silva LR, Cocco RR, Ferreira CT, Sarni RO, Oliveira LC, et al. Consenso Brasileiro sobre Alergia Alimentar: 2018-Parte 2 - Diagnóstico, tratamento e prevenção. Documento conjunto elaborado pela Sociedade Brasileira de Pediatria e Associação Brasileira de Alergia e Imunologia. Arq Asma Alerg Imunol. 2018 [acesso 2018 Maio 28]; 2(1): 39-82. Disponível em: http://www. sbp.com.br/fileadmin/user_upload/aaai_vol_2_n_01_a05_7_.pdf.

8. Vieira MC, Morais MB, Spolidoro JVN, Toporovski MS, Cardoso AL, Araújo GTB, et al. A survey on clinical presentation and nutritional status of infants with suspected cow'milk allergy. BMC Pediatrics [internet]. 2010 [cited 2018 May 24]; 10: 25. Avaliable from: https://bmcpediatr.biomedcentral.com/track/ pdf/10.1186/1471-2431-10-25.

9. Venter C, Brown T, Meyer R, Walsh J, Shah N, Nowak-Wegrzyn A, et al. Better recognition, diagnosis and management of Non-IgE-mediated cow's milk allergy in infancy: iMAP-na international interpretation of the MAP (Milk Allergy in Primary Care) guideline. Clin Transl Allergy [internet]. 2017 [cited 2018 May 24]; 7:26. Aaliable from: https://www.ncbi.nlm.nih.gov/pmc/articles/PMC5567723/ pdf/13601_2017_Article_162.pdf.

10. Vandenplas Y. Prevention and Management of Cow's Milk Allergy in NonExclusively Breastfed Infants. Nutrients [internet]. 2017 [cited 2018 May 24]; 9: 731. Avaliable from: https://www.ncbi.nlm.nih.gov/pmc/articles/PMC5537845/ pdf/nutrients-09-00731.pdf. 
11.Ministério da Saúde [BR]. Protocolo Clínico e Diretrizes Terapêuticas Alergia à Proteína do Leite de Vaca (APLV). Brasília: Ministério da Saúde; 2017 [acesso
2018 outubro 10]. Disponível em: http://conitec.gov.br/images/Consultas/ Relatorios/2017/Relatorio_PCDT_APLV_CP68_2017.pdf. 